\title{
Parking Pull In The Taman Pasuk Kameluh Tourism Area (Street S. Parman, Palangka Raya City)
}

\section{Tarikan Parkir Dikawasan Wisata Taman Pasuk Kameluh (Jalan S. Parman Kota Palangka RAYA)}

\author{
Jeki $^{1}$, Lola Cassiophea ${ }^{2}$, Wiratno ${ }^{3}$ \\ ${ }^{1}$ Mahasiswa Program Studi Pendidikan Teknik Bangunan \\ ${ }^{23}$ Dosen Program Studi Pendidikan Teknik Bangunan Universitas Palangka Raya \\ e-mail: jheck890@gmail.com
}

\begin{abstract}
This type of research used in this research is descriptive research with a qualitative approach. The data needed to complete this research includes primary data obtained from field surveys which are used to obtain parking attraction and parking space capacity, while secondary data is obtained from the Perkim Service (Public Housing and Settlement Service) Palangka Raya City. The results of this study indicate that, Parking Space Capacity $=53 \div 0.75=70.6$ motorbikes $=71$ motorbikes, the highest parking accumulation is on Sunday at 15.00 WIB - 16.00 WIB for 62 motorbikes, the highest parking volume on Sunday is 258 vehicles/days/space, parking turnover rate (trun over) $=258 \div 145=1.7$ vehicles/day/space, the average parking index per day is $10.71 \%$, $11.41 \%, 6.1 \%$, and park parking needs are $33 \times 53=1,749 \mathrm{~m} 2$. Based on the results of the calculation of the parking attraction that occurs in the Taman Pasuk Kameluh area, Palangka Raya City, it is 258 vehicles/day/space. For travel attraction compared to the number of motorbike parking lots available to accommodate vehicles in the Kasuk Kameluh park area, it is 70.6 vehicles/day. So based on the results obtained, the demand for parking space exceeds the existing parking capacity, only 53 parking pedals (demand) exceed the existing parking capacity.
\end{abstract}

Keywords: Parking Pull, Parking Space Requirements, Motorbikes.

\section{PENDAHULUAN}

Kota Palangka Raya merupakan sebuah kota sekaligus Ibu Kota Provinsi Kalimantan Tengah. Kota ini memiliki luas wilayah $2.400 \mathrm{~km}^{2}$ dan berpenduduk sebanyak 376.647 jiwa dengan kepadatan penduduknya rata-rata 2.067 jiwa tiap $\mathrm{km}^{2}$ sensus penduduk 2015, sebelum otonomi daerah pada tahun 2001 Kota Palangka Raya hanya memiliki dua kecamatan, yaitu kecamatan Pahandut dan kecamatan Bukit Batu. Pada tahun 2017 kota Palangka Raya bertambah tiga kecamatan, secara administratif kota Palangka Raya memiliki lima kecamatan yang diakui yaitu: Pahandut, Bukit Batu, Jekan Raya, Sabangau dan Rakumpit. Dari tahun ke tahun jumlah pertumbuhan penduduk di kota Palangka Raya mengalami peningkatan, sehingga aktivitas kegiatan manusia pun turut bergerak pula seiring dengan laju pertumbuhan penduduk tersebut. Dengan lajunya angka pertumbuhan penduduk, maka tingkat kepemilikan kendaraan bermotor baik roda dua maupun roda empat semakin meningkat pula, akibatnya volume lalu lintas dan kepadatannya pun turut naik. Laju jumlah kendaraan yang terus bertambah ini ternyata belum seimbang dengan tersedianya sarana dan prasarana transportasinya, salah satunya adalah penyediaan areal parkir yang cukup memadai pada suatu kawasan pertamanan.

Pelayanan parkir yang kurang baik seperti pada Taman Pasuk Kameluh Kota Palangka Raya membuat sebagian besar kendaraan parkir pada bahu jalan raya, yang mana menyebabkan tidak nyaman dan tidak aman bagi orang yang melintasi taman tersebut. Kebutuhan parkir pada taman sangat tergantung pada banyaknya 
jumlah pengunjung yang datang ke Taman Pasuk Kameluh, semakin besar jumlah pengunjung yang datang ketaman Pasuk Kameluh maka semakin banyak fasilitas parkir yang harus disediakan begi pengunjung yang datang, maupun kelengkapan fasilitas parkir.

Berdirinya tempat wisata pada kawasan pusat kota, yaitu Taman Pasuk Kameluh menimbulkan dampak yang negatif terhadap pergerakan yang ada di sekitarnya, karena jalan raya dua arah yang ramai, yang menyebab lalu lintas di kawasan tersebut menjadi ramai dan macet, serta mengganggu pengguna jalan lain yang melewati jalan pada sekitar Taman Pasuk Kameluh dikarenakan parkir yang masih belum teratur serta menggunakan bahu jalan raya sebagai tempat parkir kendaraan.

Pengunjung taman yang datang masih belum sadar untuk memarkirkan kendaraannya dengan benar, serta kendaraan tidak diparkir pada tempat parkir yang sudah disediakan oleh petugas parkir taman pasuk kameluh. Adapun lokasi Taman Pasuk Kameluh yang berada dipusat Kota Palangka Raya, serta berada pada samping Jembatan Kahayan, serta sungai Kahayan sehingga menjadi daya tarik tersendiri bagi para pengunjung untuk bersantai serta beribadah pada Masjid Kubah Kerucut yang dibangun tidak jauh dari taman tersebut.

Berdasarkan permasalahan diatas, maka perlu adanya penelitian tentang "Tarikan Parkir Pada Kawasan Wisata Taman Pasuk Kameluh (Jalan S. Parman Kota Palangka Raya)", sehingga diharapkan dalam penataan pada parkir taman Pasuk Kameluh kedepannya akan menjadi lebih baik.

\section{METODELOGI PENELITIAN}

Penelitian ini menggunakan metode survei langsung di lapangan yang dilaksanakan selama 3 hari (jumat, sabtu dan minggu dengan analisis data secara deskritif kualitatif. Penelitian deskriptif adalah suatu bentuk penelitian yang ditujukan untuk mendeskripsikan fenomena-fenomena yang ada, baik fenomena alamiah maupun fenomena buatan manusia (Sukmadinata, 2009). Penelitian deskriptif dilakukan untuk mengetahui nilai variabel mandiri baik satu variabel atau lebih (independen) tanpa membuat perbandingan atau menghubungkan dengan variabel yang lain (Sugiyono, 2014). Sampel adalah sebagian atau wakil dari populasi yang akan diteliti (Arikunto, 2007). Sampel penelitian adalah semua jumlah kendaraan roda dua yang ada di lokasi parkit Taman Pasuk Kameluh.

1. Kapasitas Ruang Parkir adalah daya tampung kendaraan yang parkir di areal parkir yang tersedia. Kapasitas ruang parkir dapat dihitung dengan persamaan 1:

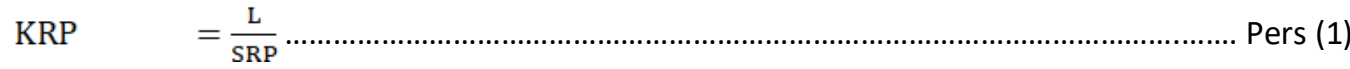

Keterangan:

KRP $\quad=$ Kapasitas Ruang Parkir

L $\quad$ = Luas Lahan Parkir

SRP = Satuan Ruang Parkir Hobbs, F.D.1995 dalam kutipan Muhammad Zaim Madani 2019

2. Volume parkir adalah jumlah kendaraan yang menggunakan ruang parkir pada suatu lahan parkir tertentu. Volume parkir dapat dihitung dengan menjumlahkan kendaraan yang menggunakan areal parkir dalam waktu tertentu.

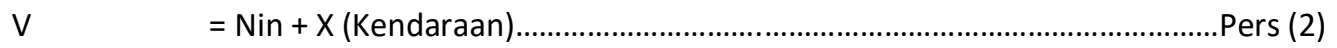

Keterangan: $\quad$ = Jumlah kendaraan mesuk

Nin $\quad=$ Volum

$X \quad=$ Jumlah kendaraan yang ada sebelum survei (Hobbs, F.D. 1995 dalam

kutipan Muhammad zaim Madani 2019

3. Akumulasi Parkir $=$ Qin - Qout + Qs Pers (3) Keterangan:

Qin $\quad=$ Jumlah kendaraan yang masuk lokasi parkir

Qout $\quad=$ Jumlah kendaraan yang keluar lokasi parkir

Qs $\quad=$ Jumlah kendaraan parkir sebelum pengamatan Hobbs, F.D. 1995 dalam kutipan Muhammad Zaim Madani 2019

4. Tingkat turn over adalah laju pergantian ruang parkir pada periode tertentu yang diperoleh dengan 
ISSN 2443-227X

persamaan:

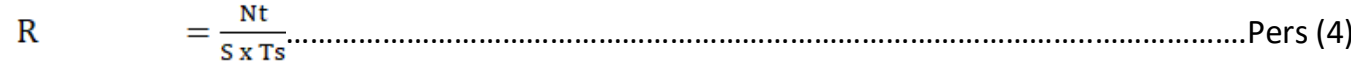

Keterangan:

$\mathrm{R} \quad \quad=$ Pergantian parkir

$\mathrm{S} \quad=$ Jumlah petak parkir

Nt $\quad=$ Jumlah kendaraan saat dilakukan survei

Ts $\quad=$ Lama periode parkir saat survei Hobbs, F.D 1995 dalam kutipan Muhammad Zaim Madani 2019

5. Indeks Parkir adalah presentase dari jumlah kendaraan yang parkir di areal parkir dengan jumlah parkir yang tersedia. Indeks parkir dapat dihitung dengan persamaan:

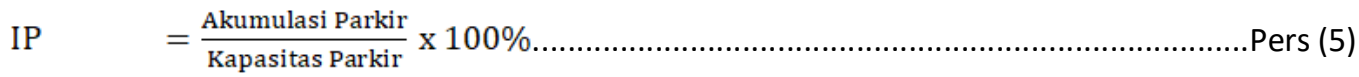

6. Durasi Parkir adalah rentang waktu sebuah kendaraan yang parkir di suatu tempat (dalam satuan menit atau jam), nilai durasi parkir diperoleh dengan persamaan:

D $\quad=\frac{\sum(\mathrm{fxx})}{\sum \mathrm{f}}$. ..Pers (6)

Keterangan:

D = Durasi rata-rata parkir

$\mathrm{F} \quad \quad=$ Jumlah petak parkir

$\mathrm{X}=$ Jumlah kendaraan saat dilakukan survei

7. Kebutuhan ruang parkir efektif merupakan luas area yang dibutuhkan berdasarkan akumulasi kendaraan tertinggi, kebutuhan ruang parkir efektif dapat dihitung dengan persamaan:
KRP
$=\mathrm{JK} \times \mathrm{SRP}$. Pers (7) V
Nin $\quad=$ Volum
X $\quad=$ Jumlah kendaraan yang ada sebelum survei (Hobbs, F.D. 1995 dalam kutipan Muhammad

\section{HASIL DAN PEMBAHASAN}

Dari hasil penelitian yang dilaksanakan di lokasi Kawasan Taman Pasuk Kameluh Kota Palangka Raya selama 3 hari penelitian didapatkan data primer yang direkap pada tabel 9, 10 dan 11:

Tabel 9. Data Primer Kendaraan Keluar-Masuk Taman Pasuk Kameluh Jumat, 05 Februari 2021

\begin{tabular}{|c|c|c|}
\hline & \multicolumn{2}{|c|}{ Universitas Palangka Raya } \\
\hline & \multicolumn{2}{|c|}{ Palangka Raya } \\
\hline & \multicolumn{2}{|c|}{ Fakultas FKIP } \\
\hline & \multicolumn{2}{|c|}{$\begin{array}{l}\text { Rekapitulasi Hasil Survei Parkir Taman Pasuk } \\
\text { Kameluh }\end{array}$} \\
\hline Kawasan & \multicolumn{2}{|c|}{ : Taman Pasuk Kameluh } \\
\hline Hari dan Tanggal & \multicolumn{2}{|c|}{ : Jumat, 05 Februari 2021} \\
\hline \multirow[t]{2}{*}{ Periode 1 Jam } & Arah Masuk & Arah Keluar \\
\hline & Motor (MC) & Motor (MC) \\
\hline $15: 00-16: 00$ & 13 & 3 \\
\hline $16: 00-17: 00$ & 26 & 10 \\
\hline 17:00-18:00 & 25 & 18 \\
\hline 18:00-19:00 & 30 & 25 \\
\hline 19:00-20:00 & 33 & 28 \\
\hline 20:00-21:00 & 18 & 47 \\
\hline Total & 154 & 131 \\
\hline
\end{tabular}


(Sumber: Data Penelitian 2021)

Tabel 10. Data Primer Kendraan Keluar-Masuk Taman Pasuk Kameluh Sabtu 06 Februari 2021

\begin{tabular}{|c|c|c|}
\hline & \multicolumn{2}{|c|}{ Universitas Palangka Raya } \\
\hline & \multicolumn{2}{|c|}{ Palangka Raya } \\
\hline & \multicolumn{2}{|c|}{ Fakultas FKIP } \\
\hline & \multicolumn{2}{|c|}{$\begin{array}{l}\text { Rekapitulasi Hasil Survei Parkir Taman Pasuk } \\
\text { Kameluh }\end{array}$} \\
\hline Kawasan & \multicolumn{2}{|c|}{ : Taman Pasuk Kameluh } \\
\hline Hari dan Tanggal & \multicolumn{2}{|c|}{ : Minggu, 06 Februari 2021} \\
\hline \multirow{2}{*}{ Periode 1 Jam } & Arah Masuk & Arah Keluar \\
\hline & Motor (MC) & Motor (MC) \\
\hline $15: 00-16: 00$ & 19 & 16 \\
\hline 16:00-17:00 & 18 & 14 \\
\hline 17:00-18:00 & 21 & 8 \\
\hline 18:00-19:00 & 19 & 35 \\
\hline 19:00-20:00 & 59 & 21 \\
\hline 20:00-21:00 & 0 & 42 \\
\hline Total & 136 & 136 \\
\hline
\end{tabular}

(Sumber: Data Penelitian 2021)

Tabel 11. Data Primer Kendraan Keluar-Masuk Taman Pasuk Kameluh Minggu 07 Februari 2021

\begin{tabular}{|c|c|c|}
\hline & \multicolumn{2}{|c|}{ Universitas Palangka Raya } \\
\hline & \multicolumn{2}{|c|}{ Palangka Raya } \\
\hline & \multicolumn{2}{|c|}{ Fakultas FKIP } \\
\hline & \multicolumn{2}{|c|}{$\begin{array}{l}\text { Rekapitulasi Hasil Survei Parkir Taman Pasuk } \\
\text { Kameluh }\end{array}$} \\
\hline Kawasan & \multicolumn{2}{|c|}{ : Taman Pasuk Kameluh } \\
\hline Hari dan Tanggal & \multicolumn{2}{|c|}{ : Minggu, 07 Februari 2021} \\
\hline \multirow[t]{2}{*}{ Periode 1 Jam } & Arah Masuk & Arah Keluar \\
\hline & Motor (MC) & Motor (MC) \\
\hline $15: 00-16: 00$ & 44 & 14 \\
\hline $16: 00-17: 00$ & 63 & 32 \\
\hline $17: 00-18: 00$ & 53 & 61 \\
\hline 18:00-19:00 & 39 & 40 \\
\hline $19: 00-20: 00$ & 37 & 59 \\
\hline 20:00-21:00 & 18 & 45 \\
\hline Total & 254 & 251 \\
\hline
\end{tabular}

(Sumber: Data Penelitian 2021)

1. Akumulasi Parkir

Akumulasi parkir dibutuhkan untuk mengetahui jumlah kendaraan yang parkir pada lahan yang tersedia dengan selang waktu tertentu. Data ini diperoleh dengan cara menghitung kendaraan yang telah menggunakan lahan parkir ditambah dengan kendaraan yang masuk dan dikurangi dengan kendaraan yang keluar, maka akan didapat jumlah maksimum dari kendaraan yang parkir pada hari dan waktu tertentu. Hasil perhitungan akumulasi parkir pada hari jumat sampai dengan minggu adalah sebagai berikut: 


\begin{tabular}{|c|c|c|c|}
\hline \multirow{2}{*}{ Jam } & \multicolumn{3}{|c|}{ Akumulasi Pakir } \\
\cline { 2 - 4 } & Jumat & Sabtu & Minggu \\
\hline $15: 00-16: 00$ & 14 & 7 & 34 \\
\hline $16: 00-17: 00$ & 30 & 11 & 62 \\
\hline $17: 00-18: 00$ & 37 & 24 & 57 \\
\hline $18: 00-19: 00$ & 42 & 8 & 34 \\
\hline $19: 00-20: 00$ & 47 & 46 & 7 \\
\hline 20:00-21:00 & 18 & 4 & \\
\hline
\end{tabular}

Berdasarkan perhitungan dari persamaan 3 diperoleh akumulasi parkir pada Taman Pasuk Kameluh selama 3 hari yaitu 47 kend/hari/ruang pada hari jumat, hari sabtu 46 kend/hari/ruang, dan untuk hari minggu kendaraan maksimum sebesar 62 kend/hari/ruang, dapat dilihat pada tabel 11 dan gambar 20.

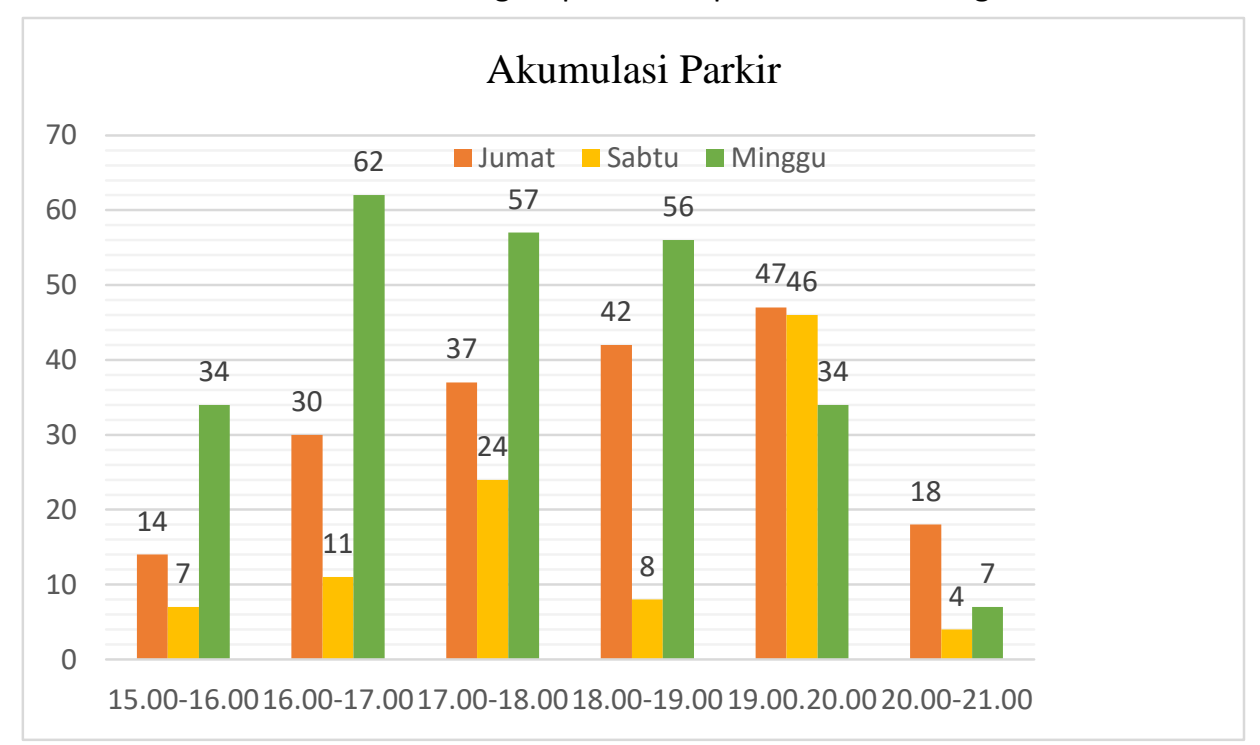

Gambar 20. Hasil Perhitungan Akumulasi Parkir

2. Volume Parkir

Volume parkir sepeda motor Paseuk Kameluh dapat dilihat pada Tabel 13 dan dijelaskan pada Gambar 21. Hasil perhitungan untuk mencari volume parkir sepeda motor pada hari jumat yaitu:

Tabel 13. Volume Kendaraan

\begin{tabular}{|c|c|c|}
\hline Jenis Kendaraan & Hari & Volume Kendaraan \\
\hline \multirow{3}{*}{ Motor } & Jumat & 149 \\
\cline { 2 - 3 } & Sabtu & 140 \\
\cline { 2 - 3 } & Minggu & 258 \\
\hline
\end{tabular}

(Sumber: Data Penelitian 2021)

Nilai hasil perhitungan volume parkir selama tiga hari observasi, hari jumat 149 kendaraan, sabtu 140 kendaraan dan hari minggu 258 kendaraan, yang datang ketaman pasuk kameluh. Untuk menghitung volume parkir guanakan persamaan (2) $\Sigma$ kendaraan masuk parkir $+\sum$ kendaraan yang sudah ada, untuk kendaraan yang sudah ada saya menggunakan angka 4 lalu dijumlahkan dengan kendaraan yang masuk pada area parkir tersebut.

Dari analisis tersebut dapat dituangkan dalam grafik Volume kendaraan, dapat dilihat pada gambar 21: 


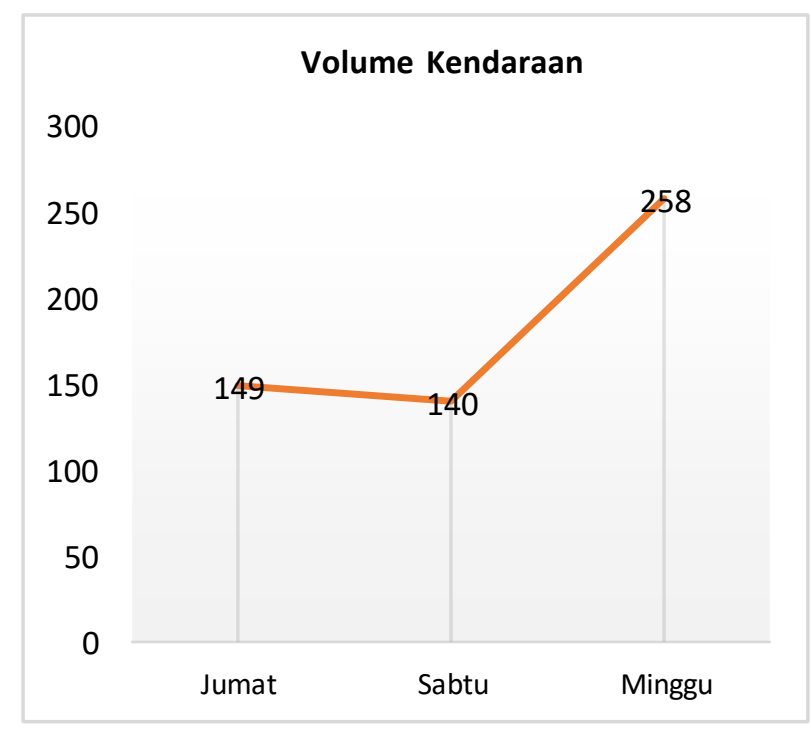

Gambar 21. Volume Parkir Sepeda Motor

Hasil pengamatan pada penelitian ini menunjukkan bahwa volume terbesar yang masuk areal parkir Pasuk Kameluh, untuk kendaraan sepeda motor terjadi pada hari minggu yaitu 62 kendaraan. Perbedaan volume kendaraan sepeda motor yang masuk pada hari jumat dan Sabtu mengalami kenaikan 5 kendaraan.

3. Kapasitas Ruang Parkir sepeda motor pada Pasuk Kameluh Palangka Raya yaitu: KRP $=53 \div 70,6$ sepeda motor $=70$ kend

4. Tingkat Turnover parkir atau angka penggunaan ruang parkir, yaitu dimaksudkan untuk melihat tingkat pemakaian ruang parkir kendaraan dalam satu hari. Tingkat turnover kendaraan yang parkir sepeda motor pada Pasuk kameluh dapat dilihat pada Tabel 14. Ruang parkir yang tersedia berdasarkan jumlah petak parkir untuk sepeda motor adalah 258. Hasil perhitungan turnover sepeda motor pada hari jum'at adalah: Tingkat turnover $=$ Volume parkir $\div$ Ruang parkir yang tersedia.

$=258 \div 149=1,7 \mathrm{kend} / \mathrm{hari} / \mathrm{ruang}$

Tabel 14. Tingkat Turnover Sepeda Motor

\begin{tabular}{|c|c|c|}
\hline $\begin{array}{c}\text { Jenis } \\
\text { Kendaraan }\end{array}$ & Hari & Turn Over \\
\hline \multirow{2}{*}{ Motor } & Jumat & 1,7 \\
\cline { 2 - 3 } & Sabtu & 1,8 \\
\cline { 2 - 3 } & Minggu & 1.0 \\
\hline
\end{tabular}

Tingkat turnover diperoleh dari hasil perhitungan yang menggunakan persamaan 4 (Volume Parkir $\div$ Ruang Parkir) maka didapat nilai pergantian parkir perharinya. Jadi pergantian perkir maksimal pada hari jumat 1.7 kend, hari sabtu 1.8 keng dan hari minggu 1.0 kend/hari/ruang.

5. Indeks parkir adalah persentase kendaraan yang menggunakan pelataran parkir dengan jumlah areal parkir yang tersedia dalam periode waktu tertentu. Dalam penelitian yang dilakukan pada areal parkir Pasuk Kameluh perhitungan parkir menggunakan waktu interval 60 menit. Indeks parkir sepeda motor pada hari jumat, sabtu dan minggu dapat dilihat pada tabel 15 dan gambar 22. Hasil perhitungan indeks parkir sepeda motor pada hari jumat sebagai berikut:

a. Perhitungan indeks parkir sepeda motor Indeks parkir maksimal = Akumulasi maksimal $\div$ Ruang parkir tersedia $\times 100 \%=258 \div 33 \times 100 \%=$ $7.8 \%$ pers (5) 
Indeks Parkir rata-rata $=$ Akumulasi rata-rata $\div$ Ruang parkir tersedia $\times 100 \%=258 \div 24 \times 100 \%=$ $10.75 \%$. pers (5)

Tabel 15. Indeks Parkir Sepeda Motor

\begin{tabular}{|l|c|c|}
\hline \multirow{2}{*}{ Hari } & \multicolumn{2}{|c|}{ Indeks Parkir Sepeda Motor \% } \\
\cline { 2 - 3 } & Rata-rata & Maksimal \\
\hline Jumat & 10.75 & 7.8 \\
\hline Sabtu & 11,41 & 4.3 \\
\hline Minggu & 6.1 & 4.09 \\
\hline
\end{tabular}

(Sumber: Hasil Perhitungan Indeks Parkir Sepeda Motor)

Adapun hasil yang didapat untuk indeks parkir taman pasuk kameluh selama tiga hari obsevasi adalah 10.75\%, 11.41\% dan 6.1\% untuk rata-rata sedangkan untuk indek maksimalnya sebesar 7,8\%, 4.3\% dan $4.09 \%$. angka-angka ini diperoleh menggunakan persamaan (5).

Dari analisis tersebut dapat dituangkan dalam gambar grafik indeks parkir kendaraan, seperti gambar 22:

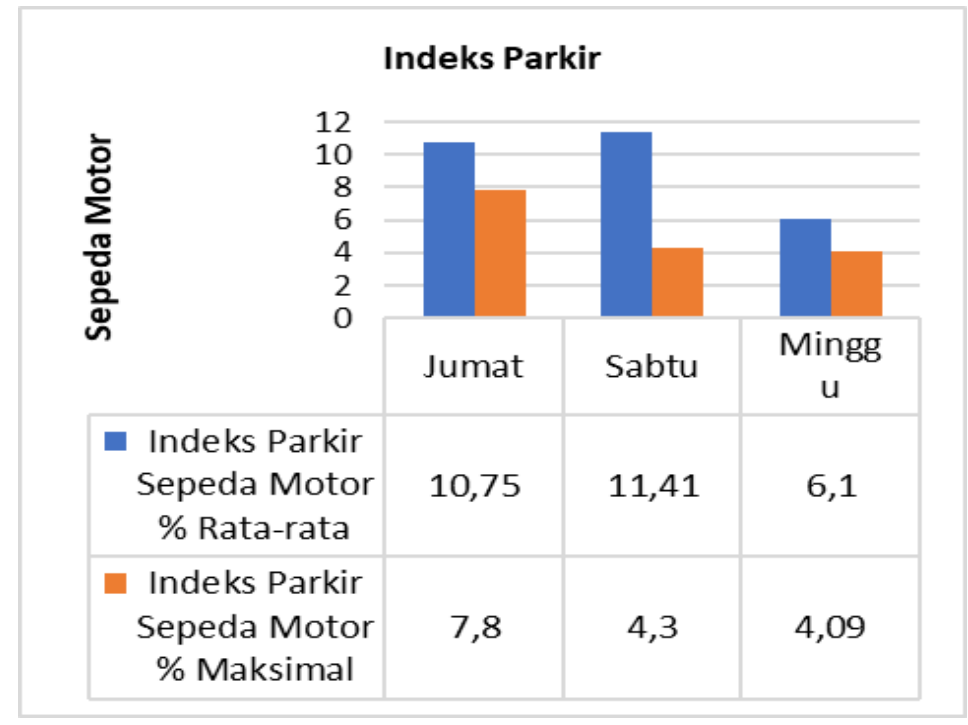

Gambar 22. Indeks Parkir Sepeda Motor

Jika nilai indeks parkir $>100 \%$, berarti permintaan ruang parkir lebih besar dari kapasitas yang ada. Jika nilai indeks parkir < $100 \%$, berarti permintaan masih dapat dipenuhi (Hobbs, 1995), dalam kutipan muhammad zaim madani 2019.

6. Hasil perhitungan kebutuhan ruang parkir sepeda motor pada jam puncak akumulasi hari jumat 33, adalah:

$\mathrm{KRP}=\mathrm{JK} \times \mathrm{SRP}=33 \times 53=1.749 \mathrm{~m}^{2}$ Pers (7)

Dari analisis didapat Kebutuhan Ruang Prkir (KRP) saat jam sibuk pada taman Pasuk Kameluh adalah 1.749 $\mathrm{m}^{2}$.

7. Durasi parkir adalah rentang waktu sebuah kendaraan parkir di suatu tempat tertentu. Pada lampiran gambar dibawah, ditampilkan durasi parkir semua kendaraan yang parkir pada areal parkir Pasuk Kameluh. Pada hari Jumat, Sabtu dan Minggu. Tanggal dan survei untuk durasi parkir sepeda motor menggunakan interval waktu 60 menit. Data analisis durasi parkir pada hari Jumat, Sabtu dan minggu dapat dilihat pada gambar 23: 
Hasil perhitungan perhitungan durasi parkir sepeda motor pada jam puncak hari jumat, sabtu dan minggu adalah:

$\mathrm{D}=$ Jumlah Petak Parkir $\mathrm{x}$ Jumlah kendaraan/Jumlah Petak Parkir

$$
=258 \times 145 / 258=145 \text {. }
$$

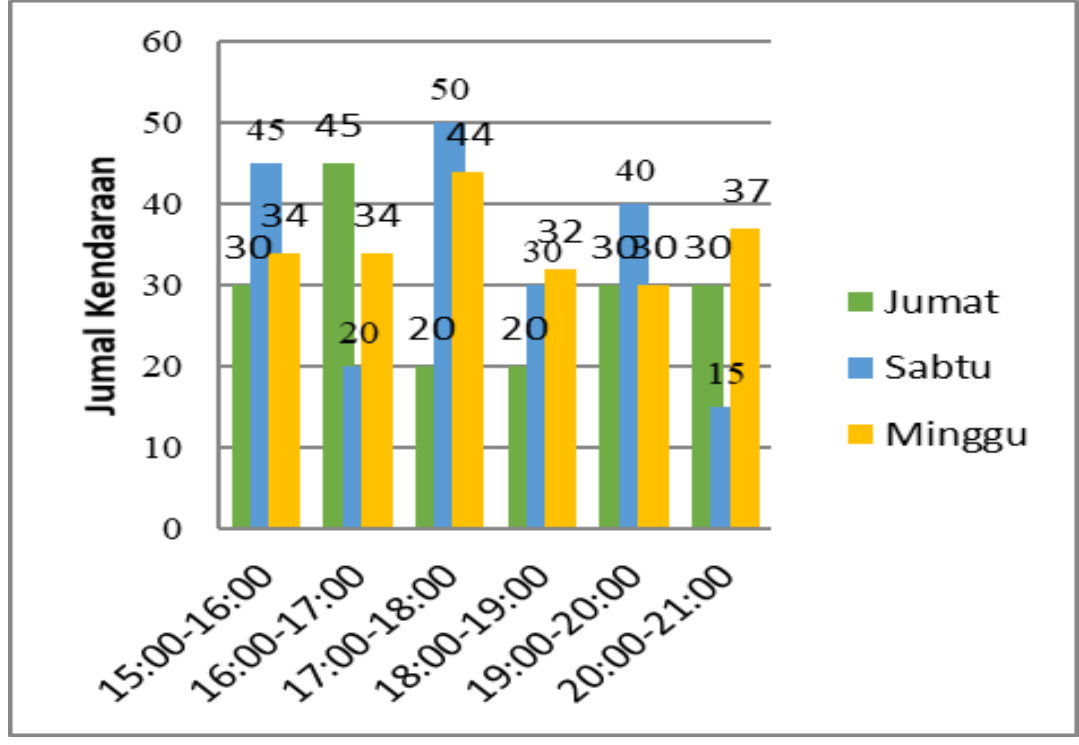

Gambar 23. Durasi Parkir Sepeda Motor

\section{PENUTUP}

\section{KESIMPULAN}

Berdasarkan hasil dari perhitungan tarikan parkir yang terjadi di Kawasan Taman Pasuk Kameluh Kota Palangka Raya adalah 258 kend/hari/ruang. Untuk tarikan perjalanan berbanding jumlah tempat parkir sepeda motor yang tersedia untuk menampung kendaraan yang hendak parkir pada kawasan taman Pasuk Kameluh sebesar 71 kend/hari/ruang. Jadi berdasarkan hasil yang diperoleh tersebut permintaan ruang parkir melebihi kapasitas parkir yang ada hanya 53 petak parkir (demand) melebihi kapasitas parkir yang ada (existing).

\section{SARAN}

1. Berdasarkan dari kesimpulan diatas peneliti menyarakan perlu dibuat tempat parkir yang baru dengan kapasitas parkir yang lebih luas dari sebelumnya supaya dapat menampung kendaraan yang datang ke Kawasan Taman Pasuk Kameluh Kota Palangka Raya.

2. Serta sebaiknya ditempatkan atau disediakan petugas parkir yang aktif (legal) pada lokasi parkir untuk untuk membantu dalam merapikan kendaraan yang parkir sehingga penyediaan tempat parkir jadi lebih efektif.

3. Perlu adanya batasan area parkir untuk memberi ruang sirkulasi bagi parkir sepeda motor, dan pemberian marka petak parkir pada area parkir kendaraan sepeda motor.

\section{DAFTAR PUSTAKA}

[1] Abubakar Iskandar. 1998. Pedoman Perencanaan Dan Pengoperasiaan Fasilitas Parkir. Jakarta: Direktorat Bina System Lalu-Lintas Dan Angkutan Kota.

[2] Arsitektur Jilid II. 2003. Jakarta: Penerbir Erlangga.

[3] Diad Raimond. 2012. Analisis Dampak Lalu-Lintas Pada Kawasan Pendidikan Ditinjau Dari Tarikan Perjalanan (Studi Khasus Pada Jalan Tamanggung Tilung Palangka Raya. Palangka Raya: Universitas Palangka Raya. 
[4] Madani, Muhammad Zaim. 2019. Perencanaan Gedung Parkir Fakultas Teknik Universitas Jember Menggunakan Stuktur Baja. Jember: Universitas Jember.

[5] Sukawi. 2008. Taman Kota Dan Upaya Pengurangan Suhu (Studi Khasus Kota Semarang). Semarang: UNDIP.

[6] Sulistiyo, Urip Puji. 2016. Analisis Kebutuhan Penyediaan Ruang Parkir Akibat Beroperasinya Rumah Sakit Kharitas Bhakti Di Jalan Siam Kota Pontianak. Pontianak: Universitas Tanjungpura.

[7] Sudiman. 2019. Analisi Tarikan Perjalanan Dan Kebutuhan Parkir Pada Halaman Universitas 17 Agustus 1945 Samarinda. Samarinda: Universitas 17 Agustus 1945.

[8] Sartika Dwi. 2020. Evaluasi Perencanaan Parkir Kawasan Tanrise City Jember. Jember: Universitas Jember.

[9] Wicaksono. 2015. Analisis Kebutuhan Ruang Parkir Paragon Mall Semarang. Semarang: Unuversitas Diponegoro.

[10] Wahidaa Nur, Renni Anggrainib Dan Muhamat Isyac. 2018. Perencanaan Kebutuhan Ruang Parkir Dikawasan Taman Sari Kota Banda Aceh. Banda Aceh: Universitas Syiah Kuala.

[11] Jumlah Kendaraan Bermotor Kota Palangka Raya Menurut Jenis dan Fungsinya, 2019. Diakses tanggal 19 Maret 2021 dari https://palangkakota.bps.go.id 